\title{
Objective assessment of corticosteroid effect in plantar fasciitis: additional utility of ultrasound
}

\author{
Asmaa Mahmoud Ali Moustafa ${ }^{1,2}$ \\ Eshrak Hassanein ${ }^{3}$ \\ Calogero Foti
}

1 Physical medicine, Rheumatology and Rehabilitation Department, Ain Shams University, Cairo, Egypt

2 Physical and Rehabilitation Medicine, Department of Clinical Sciences and Translational Medicine, "Tor Vergata" University, Rome, Italy

3 Radio-diagnosis Department, Faculty of Medicine, Ain Shams University, Cairo, Egypt

Corresponding author:

Asmaa Mahmoud Ali Moustafa

Physical and Rehabilitation Medicine, Department of Clinical Sciences and Translational Medicine, Tor Vergata University

Via di Passolombardo, 341

00133 Rome, Italy

E-mail: mhmsma01@uniroma2.it

\section{Summary}

Background: although plantar fascia thickening is well documented as a sonographic criterion for the diagnosis of plantar fasciitis (PF), however it was less evaluated as an objective measure of response to treatment. It is unknown to what extent if any different responses to different treatments are related to the ultrasound (US) morphology changes. We aimed to evaluate changes in US findings in correlation to pain reported.

Methods: this prospective observational trial included 21 plantar fasciitis patients (26 feet), resistant to conservative treatment for at least 2 months. Plantar fascia thickness and echogenicity were evaluated, compared to asymptomatic feet and correlated with visual analogue scale (VAS) and Heel Tenderness Index (HTI), before and after dexamethasone (DXM) iontophoresis in group I, and DXM injection in group II.

Results: increased thickness and reduced echogenicity were constant in symptomatic feet, with high statistical significant difference compared to asymptomatic side. Correlation between plantar fascia thickness with VAS and HTI before and after treatment showed statistically significant positive correlation $(p<0.05)$. ROC curve test showed that reduction of plantar fascia thickness by US in response to DXM had $100 \%$ sensitivity, $65.2 \%$ specificity and $69 \%$ accuracy, with higher specificity and accuracy than VAS.

Conclusion: US changes showed concurrent validity correlated with self-reported clinical improvement. Accordingly, ultrasound can be considered an objective useful tool for monitoring response to corticosteroid in patients with plantar fasciitis.

KEY WORDS: dexamethasone injection, iontophoresis, monitor treatment, plantar fasciitis, ultrasonography.

\section{Introduction}

Plantar fasciitis is the most common cause of heel pain accounting for 11 to $15 \%$ of all foot symptoms that requires professional care ${ }^{1}$. Afflicting nearly anyone stands for long time among all age groups, sexes and ethnicities ${ }^{2}$, with higher prevalence in females between 40 to 60 years ${ }^{1}$. Nowadays degenerative rather than inflammatory features of PF are clearly recognized ${ }^{3}$; for this reason, it was suggested that PF be more appropriately termed "plantar fasciosis" 4 Early initiation of conservative treatment such as shock wave therapy within 6 weeks of onset of symptoms has been recommended to hasten recovery from plantar fasciitis ${ }^{5-7}$.

Corticosteroid has been suggested if significant symptoms of plantar fasciitis persist for more than 8 weeks of conservative care ${ }^{3}$. Beside local injection iontophoresis is used an alternative modality of local, non-invasive, corticosteroids administration in treating plantar fasciitis ${ }^{2}$.

For more effective treatment of PF establishing an accurate diagnosis as early as possible is mandatory; in this regard, imaging was proposed when diagnoses is in doubt and also to rule out other causes of heel pain ${ }^{1,8}$. Plantar fasciitis is primarily soft tissue pathology and the literature clearly noted that a diagnosis cannot be made based on a heel spur on plain radiography ${ }^{9}$. Accordingly ultrasound (US) during the last years has increased its popularity as a diagnostic modality for plantar fasciitis ${ }^{10}$. Many advantages over magnetic resonance imaging (MRI) in the assessment of patients with plantar fasciitis were report$\mathrm{ed}^{8,9,11}$. Additionally it is easier and faster, more accessible and relatively inexpensive compared to any other imaging tool, therefore US is even more suitable for serial follow-ups. 
Thickening of the plantar fascia in particular has become an established sonographic criterion for the diagnosis of PF ${ }^{12,13}$. Plantar fasciitis is considered present when the plantar fascia thickness is greater than $4 \mathrm{~mm}$ or echogenicity is reduced or both ${ }^{8}$. These values have been used as a reference point in several studies ${ }^{8,9}$, also a difference of more than $1 \mathrm{~mm}$ in plantar fascia thickness between the symptomatic and asymptomatic heel of the same patient was considered as a marker for plantar fasciitis ${ }^{14}$. Hypoechogenicity was also reported in plantar fasciitis, reflecting the perifascial soft tissue edema and fluid distension of the inflamed fascia due to an active inflammatory phase secondary to degeneration or repetitive micro-tears ${ }^{15}$.

Despite the Authors postulated a decrease in the plantar fascia thickness when patients undergo treatment, the majority of the studies have been performed to evaluate US as a diagnostic tool or as a guide for minimal interventions rather than evaluating its role as an objective tool in monitoring efficacy of treatment in PF, furthermore the precise correlation between changes of facial morphology with the clinical improvement showed controversial results and was not sufficiently investigated. Moreover, it is unknown to what extent if any; different treatment modalities are related to changes in plantar fascia thickness. Therefore the purpose of this prospective study was to investigate the value of US in monitoring response to two modalities of DXM application compared to clinical improvement in subjects with PF.

\section{Methods}

This study was performed as a prospective observational trial in primary plantar fasciitis patients who were receiving their treatment in Physical medicine, Rheumatology and Rehabilitation Department of AinShams University Hospital, Cairo, Egypt. Patients were diagnosed on the basis of history taking, physical and ultrasonographic examination. They were also assessed by: laboratory investigations (ESR, fasting and postprandial blood sugar, serum uric acid), plain $\mathrm{X}$-ray both feet lateral views, the self-assessment of plantar heel pain intensity using numerical $0-10 \mathrm{~cm}$ visual analogue scale (VAS) after rest or on rising in the morning, in which 0 represented no pain, and 10 represented the worst pain subject's experience ${ }^{16}$, assessment of pain on palpation using Heel Tenderness Index (HTI) in which $0=$ no pain; 1 = painful; 2 = painful and winces; 3 = painful, winces and withdraws ${ }^{14}$, additionally body mass index (BMI) was calculated and recorded. Those who were unresponsive to one or more of conservative treatment modalities for a minimum period of 2 months, and then corticosteroid was recommended during their follow-up visits by physicians in the outpatient clinic, were recruited. Patients with contraindications of corticosteroids, local trauma or foot surgery, other causes of inferior heel pain, previous local corticosteroid injection, diabetes mellitus, and secondary plantar fasciitis as an enthesopathy associated with rheumatological diseases were excluded. Overall 25 patients were recruited, 21 female patients ( 5 bilateral cases with total of 26 symptomatic heels) were included (4 patients were excluded; 3 diabetic and 1 with lumbosacral disc herniation). To qualify for participation in the study all patients gave verbal consent to use the recorded data in their follow up sheets and to perform US assessment. The study meets the international ethical standards as described by Padulo et al. in $2013^{17}$.

All patients received dexamethasone (DXM) through two different modalities accordingly patients were randomly assigned into:

Group I: 11 patients (14 heels) received $0.4 \%$ dexamethasone iontophoresis in 10 sessions on alternating days over a period of 3 weeks, using galvanic current (Myomed 932 Enraf, Netherlands), rubber electrodes and thick spongy pads were used for ion transfer. Dexamethasone sodium phosphate solution was added to the delivering pads and was connected with the negative (cathode) electrode then placed longitudinally over the plantar aspect of symptomatic heel to repel the negatively charged DXM ions through the skin into the underlying tissue. The buffering pad soaked in water was placed proximal to the Achilles tendon and was connected to the positive electrode $(\text { anode })^{2}$. Electrodes were secured in position by bandages to ensure an even pressure over the whole area of the pad and hence uniform current density. The amplitude was slowly increased until the patient felt a prickling or tingling sensation depending on each patient's sensitivity, up to maximum $4 \mathrm{~mA}$ for 20 minutes per session ${ }^{18}$. In cases of bilateral plantar fasciitis, both feet received the session separately on the same day.

Group II: 10 patients (12 heels) received single palpation guided injection of $1 \mathrm{ml}(4 \mathrm{mg})$ dexamethasone into the area of maximum tenderness in the plantar fascia through medial approach, a 1.25 inch needle connected to a $3 \mathrm{ml}$ syringe filled with $1 \mathrm{ml}(4 \mathrm{mg})$ of dexamethasone was inserted perpendicular to the area of maximum tenderness. The needle was directly inserted down past the midline of the width of the heel. A series of minor withdrawals and repositioning were done so as to infiltrate a larger area of the inflamed fascia. Patients were instructed to avoid any strenuous activity at least 48 hours post injection, and were cautioned that they may experience worsening of symptoms during the $1^{\text {st }} 24$ to 36 hours, which could be related to a possible steroid flare ${ }^{19}$. In cases of bilateral plantar fasciitis, the other side was injected 1 week later.

Reassessment of the patients was done after the 3 weeks of sessions in group I and 3 weeks post injection in group II by: assessment of pain intensity using 0-10 numerical VAS, assessment of pain on palpation using $\mathrm{HTI}$ and US examination.

\section{Ultrasound protocol}

Ultrasonographic examination of the plantar fascia was performed at the initial assessment and 3 weeks 
after starting the treatment program for all patients by same physician $(\mathrm{EH})$ who was blind regarding which treatment was received, plantar fascia thickness and echogenicity were assessed using high resolution equipment, with a high frequency $(10 \mathrm{MHz})$ linear transducer (LOGIQ 500 pro series, GE medical systems, Germany) (Fig. 1A). Patients were examined in prone position with the foot hanging over the examination table, knee extended and ankle in $90^{\circ}$ dorsiflexion. The probe was placed over the plantar aspect of the hindfoot in a longitudinal plane with adequate amount of gel applied in-between (Fig. 1B). Images obtained just medial to the midline at proximal end of plantar fascia distal to its origin from the medial tubercle of calcaneus. Thickness of the plantar fascia was measured at the thickest portion from the base of the medial calcaneal tubercle where a bright echogenic line was easily visible. A perpendicular measurement was then taken to the top of the plantar fascia image where the most inferior border of the plantar fascia was discernable from fat. Plantar fasciitis was diagnosed when the thickness was greater than $4 \mathrm{~mm}$ or echogenicity is reduced or both 8 .

Collected data were revised, coded, tabulated and suitable analysis was done aiming to: compare the plantar fascia echogenicity and thickness between symptomatic and the contralateral asymptomatic sides, evaluate US and heel pain assessment in detecting the effectiveness of DXM in treatment of plantar fasciitis using two different application modalities (injection and iontophoresis), correlate the symptomatic improvement with the changes detected by US in plantar fascia thickness after treatment, and to determine whether changes in plantar fascia thickness are a gauge for differences in clinical response to two different treatment modalities in plantar fasciitis.

Data management was done using SPSS 15 (statistical package for the social sciences). Descriptive statistics measuring: mean, standard deviation $( \pm S D)$, minimum and maximum values (range) for numerical data, frequency and percentage of non-numerical data. Analytical statistics: student's T Test to assess the statistical significance of the difference between two groups' means. Paired t-test to assess the statistical signifi- cance of the difference between two means measured twice for the same study group. McNemar test to assess the statistical significance of the difference between binary data measured twice for a single study group. Chi-Square test X2 was used to examine the relationship between two qualitative variables. Correlation analysis (using Pearson's method) was used to assess the strength of association between two quantitative variables. The correlation coefficient denoted symbolically " $r$ " defines the strength and direction of the linear relationship between two variables. P-value level of significance: $P>0.05$ : non significant (NS), $P<0.05$ : significant (S), $\mathrm{P}<0.01$ : highly significant (HS).

\section{Results}

There were no withdrawals in our study, all patients received the treatment and followed 3 weeks later, 21 females; housewives, age ranged from 30 to 50 years with mean of $44.23 \pm 6.24$ years, BMI ranged from 27.7 to $41.7 \mathrm{~kg} / \mathrm{m}^{2}$ with a mean of $33.58 \pm 3.89 \mathrm{~kg} / \mathrm{m}^{2}$, complaint duration ranged from 2 to 10 months with mean of $3.9 \pm 1.98$ months. Out of the 21 patients 5 patients $(24 \%)$ had bilateral plantar fasciitis; the total number of feet treated was 26 feet.

Before treatment VAS ranged from 7 to 10 with a mean of 8.53 , HTI ranged from 1 to 3 with a mean of 1.75, plantar fascia thickness ranged from $4.8 \mathrm{~mm}$ to $8.9 \mathrm{~mm}$ with a mean of $5.9 \mathrm{~mm}$, the hypoechogenicity of the plantar fascia was detected in 21 feet $(80 \%)$ out of 26 symptomatic feet. Comparison between both groups regarding age, BMI, disease duration, VAS, HTI, and plantar fascia thickness using Student's t-test, and echogenicity of plantar fascia using Chi-Square showed no statistical significant difference $(p>0.05)$.

Regarding response to treatment: patients' data after last session and 3 weeks post-injection in group I and II respectively, were compared to the initial assessment; highly statistical significant changes were recorded in both groups $(p<0.01)$ regarding VAS, HTI and also in plantar fascia thickness by US using paired t-test, while McNemar test measuring echogenicity changes showed

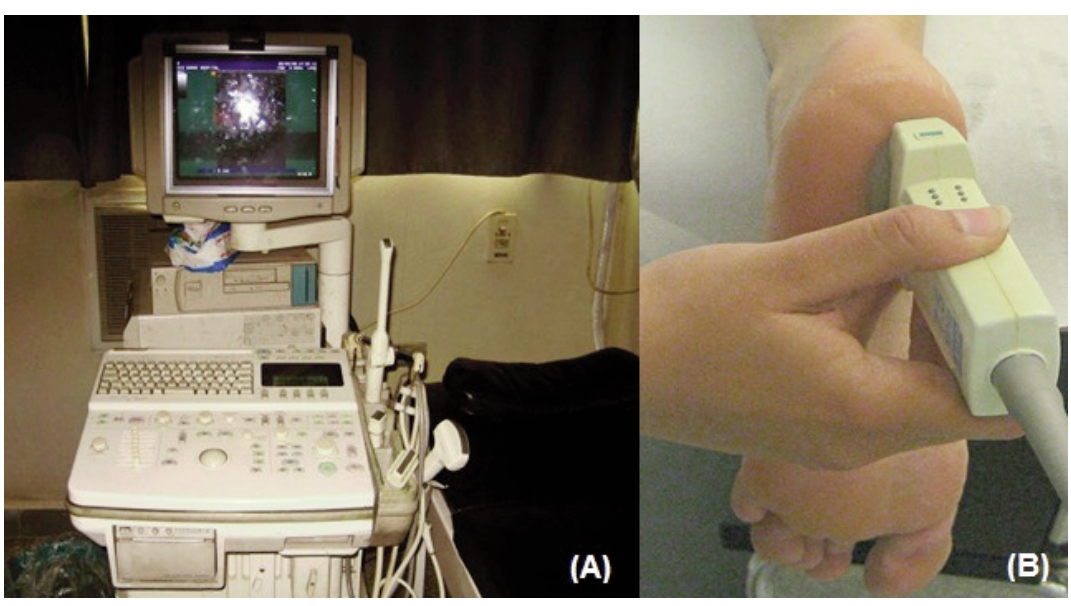

Figure 1. (A) Ultrasonography device (LOGIQ 500 pro series); (B) Sonographic transducer position for examination of the plantar fascia; Transducer is placed in the longitudinal plane of the plantar fascia medial to the midline. 
statistically significant reduction in number of feet with hypo-echogenicity after treatment $(p<0.05)$ (Tab. 1). No statistical significant difference between the two treatment modalities in both groups regarding improvement in $\mathrm{HTI}$ and US findings $(\mathrm{p}>0.05)$. However better improvement regarding VAS was statistically significant in favor of group I $(p<0.05)$ (Tab. 2).

There were 3 patients ( 3 feet, $25 \%$ ) in group II who reported no improvement neither in VAS nor $\mathrm{HTI}$; among them 2 patients (16.6\%) had steroid flare which was subsided with ice packs in 2 days. However reduction in plantar fascia thickness for these 3 patients were still reported after treatment.

\section{Regarding US assessment}

Before starting treatment program, a comparison between symptomatic feet (26 feet) and asymptomatic contralateral feet (16 feet) for plantar fascia thickness and echogenicity was done using paired t-test and Chi-Square test respectively; the results showed highly statistically significant difference $(p<0.01)$ in plantar fascia thickness with no hypoechogenicity detected in asymptomatic side (Tab. 3). Pearson's correlation coefficient was calculated to test the correlation between baseline values of VAS and HTI with the thickness of plantar fascia in all included patients, and results

Table 1. Baseline values of US findings, the intensity of pain measured using VAS and intensity of pain on palpation measured using HTI compared to values after treatment in both groups.

\begin{tabular}{|c|c|c|c|c|c|c|}
\hline Item & Before treatment & After treatment & Change & $t$ & $\mathbf{p}$ & Sig. \\
\hline \multicolumn{7}{|c|}{ GROUP I } \\
\hline \multicolumn{7}{|l|}{ VAS } \\
\hline $\begin{array}{l}\text { Mean } \pm \text { SD } \\
\text { (Min.-Max.) }\end{array}$ & $\begin{array}{l}8.5 \pm 1.2 \\
(7-10)\end{array}$ & $\begin{array}{l}4.1 \pm 1 \\
(3-6)\end{array}$ & $4.3 \pm 1.1$ & 14.16 & $<0.01$ & $H S$ \\
\hline \multicolumn{7}{|l|}{ HTI before treatment } \\
\hline $\begin{array}{l}\text { Mean } \pm \text { SD } \\
\text { (Min.-Max.) }\end{array}$ & $\begin{array}{l}1.7 \pm 0.8 \\
(1-3)\end{array}$ & $\begin{array}{l}0.7 \pm 0.4 \\
(1-3)\end{array}$ & $0.9 \pm 0.7$ & 4.75 & $<0.01$ & $H S$ \\
\hline \multicolumn{7}{|l|}{ Thickness in mm. } \\
\hline $\begin{array}{l}\text { Mean } \pm \text { SD } \\
\text { (Min.-Max.) }\end{array}$ & $\begin{array}{l}5.9 \pm 1.1 \\
(4.8-8.9)\end{array}$ & $\begin{array}{l}3.9 \pm 1 \\
(2.6-6.5)\end{array}$ & $1.98 \pm 0.6$ & 11.8 & $<0.01$ & $H S$ \\
\hline \multirow[t]{2}{*}{ Hypoechogenicity } & No. & $\%$ & No. & $\%$ & $<0.05$ & $S$ \\
\hline & 12 & 85.7 & 2 & 14.3 & & \\
\hline \multicolumn{7}{|c|}{ GROUP II } \\
\hline \multicolumn{7}{|l|}{ VAS } \\
\hline $\begin{array}{l}\text { Mean } \pm \text { SD } \\
\text { (Min.-Max.) }\end{array}$ & $\begin{array}{l}8.5 \pm 1 \\
(7-10)\end{array}$ & $\begin{array}{l}5.2 \pm 1.4 \\
(3-7)\end{array}$ & $3.3 \pm 1.3$ & 8.86 & $<0.01$ & $H S$ \\
\hline \multicolumn{7}{|l|}{ HTI } \\
\hline $\begin{array}{l}\text { Mean } \pm \text { SD } \\
\text { (Min.-Max.) }\end{array}$ & $\begin{array}{l}1.8 \pm 0.8 \\
(1-3)\end{array}$ & $\begin{array}{l}0.9 \pm 0.7 \\
(1-3)\end{array}$ & $0.9 \pm 0.5$ & 6.16 & $<0.01$ & HS \\
\hline \multicolumn{7}{|l|}{ Thickness in mm. } \\
\hline $\begin{array}{l}\text { Mean } \pm \text { SD } \\
\text { (Min.-Max.) }\end{array}$ & $\begin{array}{l}5.8 \pm 0.7 \\
(4.8-7.3)\end{array}$ & $\begin{array}{l}3.9 \pm 1 \\
(2.6-6.5)\end{array}$ & $1.6 \pm 0.8$ & 11 & $<0.01$ & HS \\
\hline \multirow{2}{*}{ Hypoechogenicity } & No. & $\%$ & No. & $\%$ & $<0.05$ & $S$ \\
\hline & 9 & 75 & 4 & 33.3 & & \\
\hline
\end{tabular}

VAS: Visual Analogue Scale

HTI: Heel Tenderness Index

Table 2. Comparison between group I and group II regarding degree of improvement in VAS, HTI and change in thickness and echogenicity of plantar fascia after treatment.

\begin{tabular}{|c|c|c|c|c|c|}
\hline Item & $\begin{array}{l}\text { Group I } \\
(\text { no=14) }\end{array}$ & $\begin{array}{l}\text { Group II } \\
(\mathrm{no}=12)\end{array}$ & $t$ & $\mathbf{p}$ & Sig. \\
\hline \multicolumn{6}{|l|}{ Change in VAS after treatment } \\
\hline Mean \pm SD & $4.3 \pm 1.1$ & $3.3 \pm 1.3$ & 2.128 & $<0.05$ & $S$ \\
\hline \multicolumn{6}{|l|}{ Change in $\mathrm{HTI}$ after treatment } \\
\hline Mean \pm SD & $0.9 \pm 0.7$ & $0.9 \pm 0.5$ & 0.047 & $>0.05$ & NS \\
\hline \multicolumn{6}{|l|}{ Change in thickness $(\mathrm{mm})$ after treatment } \\
\hline Mean \pm SD & $1.98 \pm 0.6$ & $1.6 \pm 0.8$ & 1.16 & $>0.05$ & NS \\
\hline Change in echogenicity after treatment: & No. & No. & Chi-Square & & \\
\hline Improved (from hypoechoic to hyperechoic) & 71.4 & 41.7 & 2.345 & $>0.05$ & NS \\
\hline
\end{tabular}

VAS: Visual Analogue Scale

HTI: Heel Tenderness Index 
showed statistically significant positive correlation ( $p$ $<0.05$ ) with VAS and highly statistically significant positive correlation $(p<0.01)$ with HTI (Fig. 2).

After treatment, changes of plantar fascia thickness were correlated with changes in VAS and $\mathrm{HTI}$; the results showed highly statistically significant positive correlation $(p<0.01)$ as shown in Figure 3. Moreover, validity of measurement of plantar fascia thickness was tested as an objective tool for assessment of corticosteroid efficacy in plantar fasciitis using ROC curve test. Results showed that US had $100 \%$ sensitivity with false +ve $0 \%$ and $65.2 \%$ specificity with false -ve $34.8 \%$ and $69 \%$ accuracy in detecting reduction of plantar fascia thickness after both treatment modalities with $4.05 \mathrm{~mm}$ as a cut-off point (Fig. $4 \mathrm{~A}$ ). Validity of VAS in treatment assessment was also tested using ROC curve test (Fig. 4 B).

Measuring plantar fascia thickness using US was compared to assessment of pain intensity by VAS using Chi-Square test. Results showed that there was no statistically significant difference $(P>0.05)$ between them in monitoring the efficacy of treatment, however thickness measured by US showed higher specificity and accuracy (Tab. 4).

Table 3. Comparison between symptomatic feet and asymptomatic contralateral feet regarding thickness and echogenicity of plantar fascia before treatment.

\begin{tabular}{|c|c|c|c|c|c|}
\hline Item & $\begin{array}{l}\text { Symptomatic feet } \\
(\mathrm{No}=26)\end{array}$ & $\begin{array}{l}\text { Asymptomatic feet } \\
(\mathrm{No}=16)\end{array}$ & $t$ & $\mathbf{p}$ & Sig. \\
\hline \multicolumn{6}{|l|}{ Thickness in mm } \\
\hline Mean \pm SD & $5.9 \pm 0.95$ & $3.4 \pm 0.58$ & 9.312 & $<0.01$ & $H S$ \\
\hline Echogenicity & No. & No. & Chi-Square & $<0.01$ & $H S$ \\
\hline Hypoechogenicity & 80.8 & 0 & 25.846 & & \\
\hline Hyperechogenicity & 19.2 & 100 & & & \\
\hline
\end{tabular}
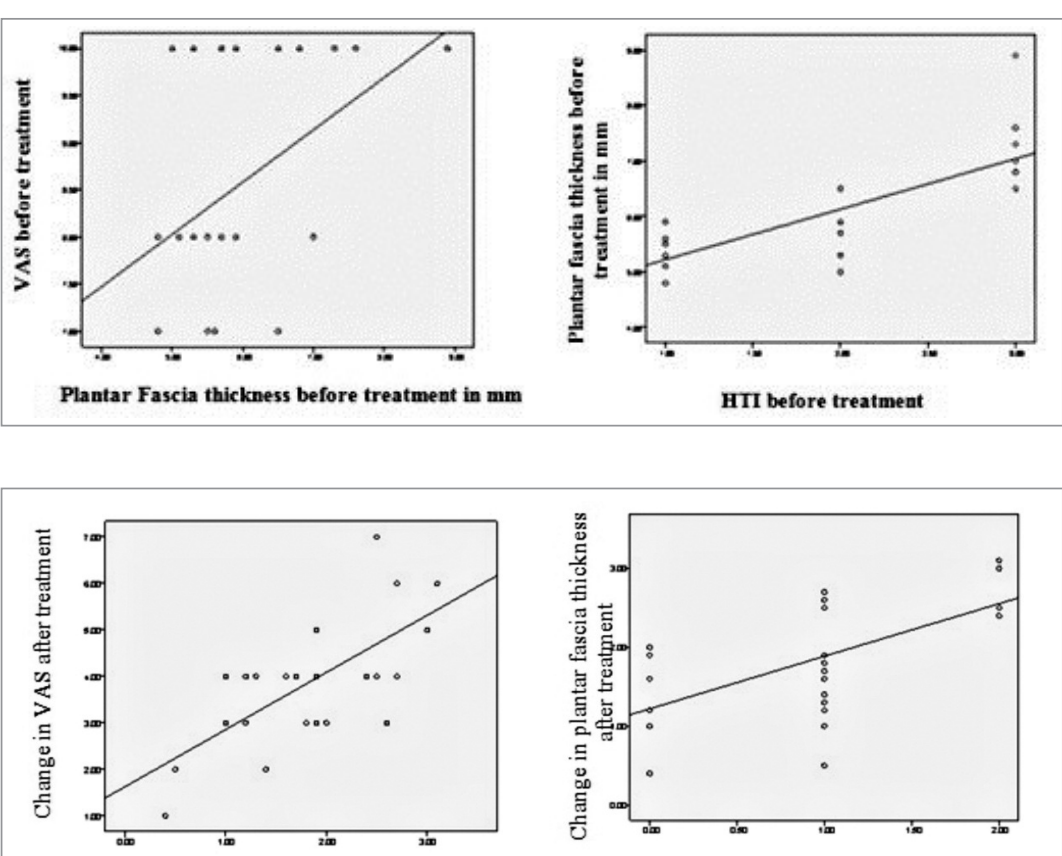

Change in plantar fascia thickness after treatment

Change in HTI after treatment
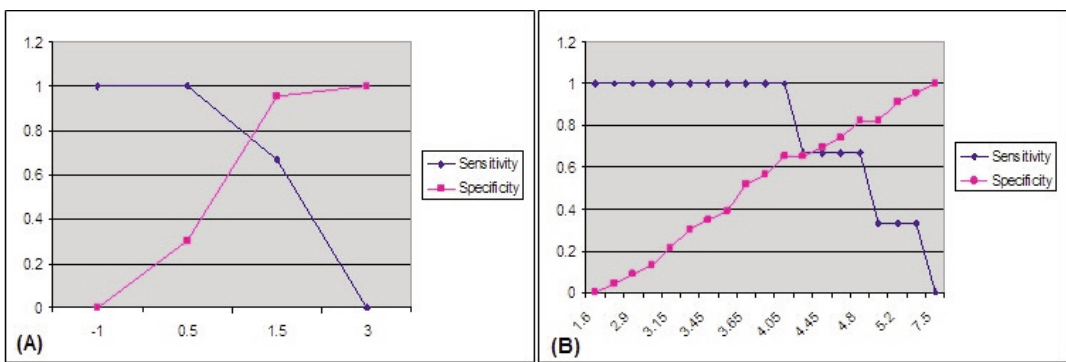

Figure 2. Correlation between baseline values of pain intensity measured by VAS and pain intensity on palpation measured by $\mathrm{HTI}$ with thickness of plantar fascia before treatment program.

Figure 3. Correlation between pain intensity measured by VAS and pain intensity on palpation measured by HTI with thickness of plantar fascia after treatment program.

Figure 4. ROC curve showing sensitivity and specificity in detecting changed plantar fascia thickness (A) and of VAS (B). 
Table 4. Comparison between the validity of measuring plantar fascia thickness by US and VAS in monitoring response to corticosteroids.

\begin{tabular}{llllll}
\hline Item & Thickness by US & VAS & Chi Square & p & Sig. \\
\hline Specificity & $65.2 \%$ & $57 \%$ & 0.322 & $>0.05$ & $N S$ \\
Sensitivity & $100 \%$ & $100 \%$ & 99.9 & $>0.05$ & $N S$ \\
False +ve & $0 \%$ & $0 \%$ & 99.9 & $>0.05$ & $N S$ \\
False -ve & $34.8 \%$ & $43 \%$ & 1.044 & $>0.05$ & $N S$ \\
Accuracy & $69 \%$ & $61.5 \%$ & 0.965 & $>0.05$ & $N S$ \\
\hline
\end{tabular}

VAS: Visual Analogue Scale

US: Ultrasound
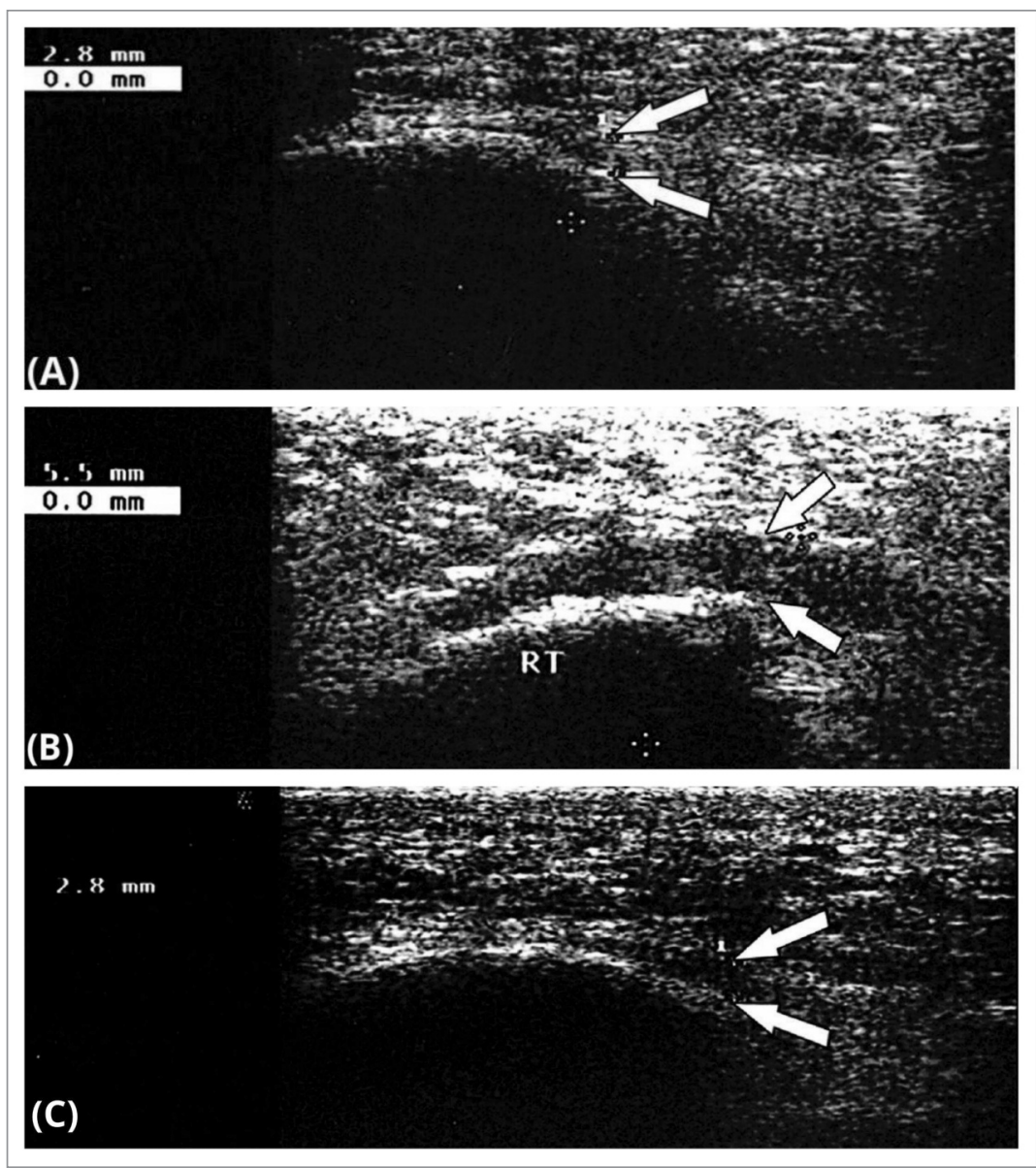

Figure 5. An example of an unilateral case of plantar fasciitis before and after treatment: (A) Asymptomatic contralateral heel with plantar fascia thickness $=2.8$ $\mathrm{mm}$ and echogenicity of the fascia; (B) before treatment plantar fascia thickness $=5.5 \mathrm{~mm}$ with hypoechogenicity of the fascia; (C) after treatment plantar fascia thickness $=2.8 \mathrm{~mm}$ with improved echogenicity of the fascia.

The statistical significant difference in improvement of VAS $(p<0.05)$ after treatment in group I compared to group II, was not consistent with US findings, moreover 3 feet $(11.5 \%)$ had a decrease in the plantar fascia thickness with no change in pain measured by VAS nor HTI.

An example of US assessment of an unilateral case of plantar fasciitis before and after treatment with DXM is demonstrated in Figure 5.

\section{Discussion}

In this study, the aim was to evaluate the utility of ultrasound in monitoring the response of plantar fasci- itis patients to DXM applied by two different modalities, and to test the correlation between plantar fascia thickness and the subjective pain assessment using VAS and HTI before and after treatment.

According to our results, increased thickness of plantar fascia was a consistent finding in patients with the clinical diagnoses of plantar fasciitis. Before treatment, the results showed that the mean plantar fascia thickness for the 26 symptomatic feet was $5.91 \pm$ $0.95 \mathrm{~mm}$ with high statistical significant difference $(\mathrm{p}$ $<0.01$ ) compared to asymptomatic contralateral feet (16 feet) which was $3.4 \pm 0.58 \mathrm{~mm}$, with no hypoechogenicity detected in asymptomatic side. This agrees with the values reported in different studies $^{12,20-22}$, where the mean plantar fascia thickness in 
symptomatic feet was $5.8 \pm 1.3 \mathrm{~mm}, 6.2 \pm 1.2 \mathrm{~mm}$, $5.7 \pm 0.9 \mathrm{~mm}, 6.1 \pm 1.09 \mathrm{~mm}, 6.1 \pm 1.4 \mathrm{~mm}$ and 6.2 $\mathrm{mm}$ and $5.71 \pm 1.33 \mathrm{~mm}$ respectively.

However, our mean thickness was higher than reported in the studies done by Akfirat et al. in 2003 and Ozdemir et al. in $2005^{23,24}$, where the mean of plantar fascia thickness was $4.75 \pm 1.52 \mathrm{~mm}$ and $2.9 \pm 0.6 \mathrm{~mm}$ respectively. This is most probably due to higher BMI in our patients which was $33.58 \pm 3.89 \mathrm{~kg} / \mathrm{m}^{2}$ versus $28.4 \pm 5.9 \mathrm{~kg} / \mathrm{m}^{2}$ and $28 \pm 3.7 \mathrm{~kg} / \mathrm{m}^{2}$ in these two studies respectively; a positive significant correlation of BMI with the thickness of the plantar fascia was reported; it was explained in literature that high BMI causes increase in vertical forces, leads to increased plantar pressure and gradual collapse of the medial longitudinal arch of the foot, which in turn increases the stress factor over the plantar fascia causes repetitive microtears and subsequent inflammation ${ }^{24}$.

Before treatment, the hypoechogenicity of the plantar fascia was found in 21 feet $(80 \%)$ out of 26 symptomatic feet. This is near the values in the study done by Genc et al. in $2005^{12}$, where hypoechogenicity was in 34 feet $(73 \%)$ out of 47 feet examined. However this percentage is different from the study done in $2005^{24}$ by Ozdemir et al. who found hypoechogenicity in 16 feet $(41 \%)$ out of 41 feet: this is may be due to higher degree of inflammation and fluid collection in our patients than their patients as denoted by the higher plantar fascia thickness in our study (5.91 \pm $0.95 \mathrm{~mm})$ compared to $(2.9 \pm 0.6 \mathrm{~mm})$ in that study, moreover the selection of our patients based on including chronic cases resistant to treatment while in that study the chronicity and resistance to treatment were not listed in the inclusion criteria.

These previous US findings denote that increased thickness of the plantar fascia and reduced echogenicity are consistent with plantar fasciitis, supporting the results of different Authors who described ultrasonography as an accurate objective tool for diagnoses of plantar fasciitis.

To measure dependence between plantar fascia thickness and pain reported by patients, Pearson correlation analysis was done before treatment program between plantar fascia thickness by US with pain intensity measured using VAS and with pain intensity on palpation measured using HTI. Results showed significant positive correlation $(r=0.46, p<0.05)$ and highly statistically significant positive correlation $(r=0.77$, $\mathrm{p}<0.01)$ respectively. This agrees with Kane et al., who in $2001^{14}$ reported that there was highly statistically significant positive correlation between clinical diagnoses of plantar fasciitis using VAS and HTI score and plantar fascia thickness measured by ultrasound. To detect to what extent thickness reduction is correlated to pain reduction after treatment, Pearson correlation coefficient was calculated after treatment, showing positive correlation of high statistical significance between VAS and HTI with plantar fascia thickness $(r=0.67, p<0.01)$ and $(r=0.58, p<0.01)$ respectively. This agrees with Genc et al., who in $2005^{12}$ reported that there was highly statistically significant correlation $(r=0.61, p<0.01)$ between the changes in plantar fascia thickness and VAS values 4 weeks after local steroid injection $(r=0.61, p<0.01)$. Although this correlation agrees also with Mahowald et al., $2011^{22}$, who stated that the average reduction in fascia thickness was $0.82 \mathrm{~mm} \pm 1.04 \mathrm{~mm}$, correlating with an average improvement in pain of $3.64 \pm 2.7$ ( $P$ $<0.005)$ after variety of conservative modalities; however this was not compatible with the study done by Fabrikant and Park, 201121, who reported absence of statistically significant correlation $(p=0.348)$ between thickness reduction in plantar fascia and reduction in reported level of pain after different treatments, although in this study both variables were associated with findings in all patients. This could be contributed to the difference between these two studies regarding the shorter average follow-up period $19.33 \pm 9.8$ days and the higher average in pain improvement in Mahowald et al., $2011^{22}$ compared to 4.29 weeks and less magnitude in pain improvement in Fabrikant and Park, 201121.

The statistical significant difference in improvement of VAS ( $p<0.05)$ after treatment in favor of group I compared to group II, was not consistent with US findings, moreover 3 feet $(11.5 \%)$ had a decrease in the plantar fascia thickness with no change in pain measured by VAS nor $\mathrm{HTI}$, this was also reported in one foot $(2.6 \%)$ in the study done by Mahowald et al., $2011^{22}$. It seems that subtle changes in fascia thickness may not be sufficient for some patients to report a change in pain level; it could be a sign of positive clinical response in longer term, however this incompatibility between US findings and pain reported by patients could be caused by evaluator error, such as measuring the fascia in a different region than the previous measurement. A larger sample population for longer follow-up duration may help to evaluate the significance of this outlier and clarify which explanation is more convenient.

The results obtained regarding validity of US showed $100 \%$ sensitivity and $65.2 \%$ specificity in detecting change in plantar fascia thickness, and $66.7 \%$ sensitivity, $82.6 \%$ specificity in detecting change of echogenicity in patients with plantar fasciitis after corticosteroids. Moreover the validity of plantar fascia thickness assessed by US was compared with the clinical assessment using VAS, and the results showed that there was no statistically significant difference $(P>0.05)$ between each of these methods in monitoring the efficacy of treatment however US showed higher specificity and accuracy. This in turn reflects the reliability of US as an objective tool in monitoring the efficacy of treatment in plantar fasciitis. It should be noted that the sample population in this study included only middle-aged females.

\section{Conclusion}

In the light of these results we can conclude that ultrasound is not only efficient in diagnoses of plantar fasciitis but also in evaluating response to effective treatment as dexamethasone in this study. Echo- 
graphic assessment was positively correlated to patients' reports of pain with high statistical significance. Although the better improvement in VAS with DXM iontophoresis and the three un-responders to DXM injection was not consistent with the US findings, still it is evident that changing thickness of plantar fascia by US is a valid tool with higher specificity and accuracy in assessment of response to treatment. This additional utility of US would give the physicians an objective guide to discover malingering patients, change the treatment or consider other causes of pain. However, more research is needed to include more patients for longer term assessment, and to test reliability of US in evaluating different clinical responses to other treatment modalities such as Extracorporeal shock wave therapy/Radial Extracorporeal shock wave therapy.

\section{References}

1. Buchbinder R. Clinical Practice. Plantar fasciitis. N Engl J Med. 2004;350(21):2159-2166.

2. Costa IA, Dyson A. The integration of acetic acid iontophoresis, orthotic therapy and physical rehabilitation for chronic plantar fasciitis: a case study. J Can Chirpor Assoc. 2007; 51(3):166-174.

3. Lee TG, Ahmad TS. Intralesional autologous blood injection compared to corticosteroid injection for treatment of chronic plantar fasciitis. A prospective, randomized, controlled Trial. Foot Ankle Int. 2007;28(9):984-990.

4. McNally EG, Shetty S. Plantar fascia: imaging diagnosis and guided treatment. Semin Musculoskelet Radiol. 2010; 14(3):334-343.

5. Young CC, Rutherford DS, Niedfeldt MW. Treatment of plantar fasciitis. Am Fam Physician. 2001;63(3):467-478.

6. Saxena A, Fournier M, Gerdesmeyer L, Gollwitzer H. Comparison between extracorporeal shockwave therapy, placebo ESWT and endoscopicplantar fasciotomy for the treatment of chronic plantar heel pain in the athlete. Muscles, Ligaments and Tendons J. 2013;2(4):312-316.

7. Notarnicola A, Moretti B. The biological effects of extracorporeal shock wave therapy (eswt) on tendon tissue. Muscles, Ligaments and Tendons J. 2012;2(1):33-37.

8. Sabir N, Demirlenk S, Yagci B, Karabulut N, Cubukcu S. Clinical utility of sonography in diagnosing plantar fasciitis. J Ultrasound Med. 2005;24(8):1041-1048.

9. Karabay N, Toros T, Hurel C. Ultrasonographic evaluation in plantar fasciitis. J Foot Ankle Surg. 2007;46(6):442-446.

10. Huerta JP, García JMA. Effect of gender, age and anthropo- metric variables on plantar fascia thickness at different locations in asymptomatic subjects. Eur J Radiol. 2007;62(3):449453.

11. Harish S, Kumbhare D, O'Neill J, Popowich T. Comparison of sonography and magnetic resonance imaging for spring ligament abnormalities. J Ultrasound Med. 2008;27(8):11451152.

12. Genc H, Saracoglu M, Nacir B, Erdem HR, Kacar M. Longterm ultrasonographic follow-up of plantar fasciitis patients treated with steroid injection. Joint Bone Spine. 2005;72(1):61-65.

13. Hammer DS, Adam F, Kreutz A, Rupp S, Kohn D, Seil R. UItrasonographic evaluation at 6-month follow-up of plantar fasciitis after extracorporeal shock wave therapy. Arch Orthop Trauma Surg. 2005;125(1):6-9.

14. Kane D, Greaney T, Shananhan M, Duffy G, Bresnihan B, Gibney $R$. The role of ultrasonography in the diagnosis and management of idiopathic plantar fasciitis. Rheumatology. 2001; 40(9):1002-1008.

15. Erdem CZ, Sarikaya S, Erdem LO, Ozdolap S, Gundogdu S MR imaging features of foot involvement in ankylosing spondylitis. Eur J Radiol. 2005;53:110-119.

16. Gurney AB, Wascher DC. lontophoresis absorption of dexamethasone sodium phosphate in human connective tissue using iontophoresis. Am J Sports Med. 2008;36(4):753-759.

17. Padulo J, Oliva F, Frizziero A, Maffulli N. Muscles, Ligaments and Tendons Journal. Basic principles and recommendations in clinical and field science research. MLTJ. 2013;4:250-252.

18. Osborne HR, Allison GT. Treatment of plantar fasciitis by Low Dye taping and iontophoresis: short term results of a double blinded, randomized, placebo controlled clinical trial of dexamethasone and acetic acid. Br J Sports Med. 2006;40(6):545549.

19. Granter R. Treatments used for musculoskeletal conditions: more choices and more evidence. In: Brukner P and Khan K, editors. Clinical Sports Medicine, 3rd ed.; New York, McGrawHill Companies. 2007;164-209.

20. Wearing SC, Smeathers JE, Sullivan PM, Yates B, Urry SR, Dubois P. Plantar Fasciitis: Are pain and fascial thickness associated with arch shape and loading? Phys Ther. 2007; 87(8):1002-1008.

21. Fabrikant JM, Park TS. Plantar fasciitis (fasciosis) treatment outcome study: plantar fascia thickness measured by ultrasound and correlated with patient self-reported improvement. Foot (Edinb). 2011;21(2):79-83.

22. Mahowald S, Legge BS, Grady JF. The correlation between plantar fascia thickness and symptoms of plantar fasciitis. J Am Podiatr Med Assoc. 2011;101(5):385-389.

23. Akfirat M, Sen C, Gunes T. Ultrasonographic appearance of the plantar fasciitis. Clin Imaging. 2003;27(5):353-357.

24. Ozdemir H, Yilmaz E, Murat A, Karakurt L, Poyraz AK, Ogur E. Sonographic evaluation of plantar fasciitis and relation to body mass index. Eur J Radiol. 2005;54(4):443-447. 